\title{
Teosofi al-Suhrawardi al-Maqtul dan Mahzab Iluminasionisme dalam Filsafat Islam
}

\author{
Khairul Amin \\ Fakultas Filsafat, Universitas Gadjah Mada, Yogyakarta \\ Corresponding Author, e-mail: Khairular1996@gmail.com
}

\begin{abstract}
Islamic mysticism (Sufism) developed rapidly systematically (theosophy) and widely after the birth of speculative theology ('ilm al-kaläm). The development is considered to have reached its peak in the hands of Syihab Al-Din Suhrawardi Al-Maqtul (d. 1191 AD) and Muhy Al-Din Ibn 'Arabi (d. 1240 AD). These two Sufi-philosophers that gave a new color that had a different nuance from the muhadditsun, mutakallimun, philosophers, and also a number of Sufis who were strongly tied to text traditions. Although both of them also have a basis of text, their interpretation is so broad, they also have different nuances. Especially the first name has a unique journey in his career, thought and life. Suhrawardi is proposing criticism as well as trying to create a synthesis as a form of criticism and renewal of thoughts that developed before his time. Inspired by the concept of light from the Koran and Al-Ghazali's Misykat, he tried to connect what he encountered with ancient knowledge while exploring new knowledge, especially regarding the concepts and systems of light, resulting in his new theosophy called Philosophy of Isyraq. This paper will discuss the profile, context, and thoughts of Suhrawardi, especially regarding his Divine Philosophy idea which is based on light.
\end{abstract}

Keywords: Suhrawardi Al-Maqtul, light, Ilumination, Isyraq

This is an open access article distributed under the Creative Commons 4.0 Attribution License, which permits unrestricted use, distribution, and reproduction in any medium, provided the original work is properly cited (C) 2018 by author.

\section{Pendahuluan}

Teosofi Islam mencapai tahap perkembangan sistematisnya selepas periode filsafat dan teologi spekulatif (kaläm), khususnya mazhab paripatetik. Penerjemahan besar-besaran karya filsafat Yunani pada era Abbasiyah (Graeco-Arabic Translation) membawa dampak signifikan terhadap diskusi serius dalam internal umat Islam. Kegiatan memunculkan beberapa golonganm, diantaranya (1) penerima tradisi Yunani, baik kalangan yang menerima secara per se ataupun menyeleksinya secara kritis, (2) ahli hadis, dan (3) teolog spekulatif. Penerjemahan ini secara signifikan terjadi di era Al-Manshūr, Al-Mahdi, dan Al-Ma'mūn. Penerjemahan ini ditopang oleh dukungan politis penguasa serta ketertarikan masyarakat. Dalam pandangan yang lebih makro, teks-teks Yunani sampai ke masyarakat Arab dengan jalan yang kompleks, dimana sifat interdepedensi terlihat dengan jelas lewat pertemuan dengan peradaban-peradaban lainnya melalui jalan niaga dan penyebaran keyakinan, seperti lewat tradisi Suryani, Nestorian, Hindi, dan lainnya (Gutas, 2005, 1998; O'leary, 2016) .

Mengacu pada pembagian Alparslan Acikgenc, teosofi Islam hadir selepas periode disipliner (The Disciplinary Stage and The Rise of Islamic Scientific Tradition). Pada periode ini dapat dikatakan dialektika yang terjadi sudah mencapai level sekunder, dalam artian dialog dan kritik yang berkembang dilandasi oleh keilmuan yang berkembang pada tahap disipliner. Dalam teori besar Alparslan, terdapat tiga tahap awal perkembangan keilmuan dan tradisi intelektual muslim, yaitu fase pembentukan alam pandang, fase problematik, dan fase disipliner-penamaan. Adapan fase-fase ini terjadi dalam 3 kerangka pikiran, yaitu (i) Worldview, (ii) Islamic Scientific Conceptual Scheme, dan (ii) Specific Islamic Scientific Conceptual Scheme (Acikgenc, 1996, 2014). Dinamika perkembangan Intektual yang memunculkan aliran teologi, filsafat, sufisme, dan teosofi tidak lepas dari faktor eksternal yang selanjutnya 
menjadi faktor eksternal dialektis-argumentatif. Dialektika singkat embrio ketiganya hingga bentuk disiplinnya dapat merujuk gambaran transmisi dan transformasi dialektis secara historis. Dalam kasus teosofi, reproduksi wacana pemikiran merupakan hasil dari 'penyatuan' (dialektika) antara teologi, tasawuf, dan filsafat (Fakhry, 2000; Rahman, 2002; Saeed, 2004).

Dua pemikir paling terkemuka dalam teosofi Islam ialah Suhrawardi Al-Maqtūl (w. 1191 M) dan Ibn 'Arabi (w. 1240 M). Nama pertama, dikenal dengan tentang pemikiran isyraq-nya lewat karya-karya, utamanya karya terakhir dari magnum opus tetraloginya, Hikmah Al-Isyrāq. Ia didaulat sebagai guru besar filsafat ilmunasi dengan julukan Syaikh Al-Isyrāq. Nama kedua, dikenal model nalar 'irfäni (gnosis)-nya, termasuk konsep Wahdat Al-Wujud (kesatuan wujud), utamanya lewat magnum opus-nya, Futūhat Al-Makiyyah dan Fushush Al-Hikām juga sejumlah tulisannya yang lain. Ia digelari sebagai Syaikh Al-Akbār. Nama kedua, secara umum dapat dikatakan lebih terkenal daripada nama pertama, termasuk pengaruhnya di Dunia Melayu yang diantaranya tercermin lewat pemikiran Hamzah Fansuri. Diantara kajian serius terhadap dilakukan oleh S.M.N Al-Attas lewat karyanya, The Mysticism of Hamzah Fansūri (Al-Attas, 1963, 1966).

Meskipun begitu, teosofi Suhrawardi mendapat pengikutnya tersendiri. Mazhabnya sering disebut Isyraqi dan pengikutnya disebut Isyraqiyyun. Secara khusus mengenai sejarah-sejarah, ajaran, pengikut, dan perkembangannya lihat Mehdi Amin Razavi, Suhrawardi and The School of Illumination, Pikirannya tetap diterima dan dipertimbangkan ulang, walaupun ada jarak yang terputus antara pensyarahnya hingga kemunculan sejumlah pengkaji kontemporer pengkaji. Artinya, meskipun pernah 'terkubur', pemikirannya tergali Kembali (Razavi, 1997; Nasr \& Leaman, 2003). Hal ini dapat dipahami, sebab pemikiran Suhrawardi begitu kontroversial, dan masa selepasnya, terjadi pemurnian besar-besaran terhadap tasawuf di kalangan Sunni terutama, termasuk kemunculan Ibn Taimiyyah (w. $1328 \mathrm{M}$ ). Tulisan ini berusaha mengulas dan memberikan beberapa catatan terhadap gagasan teosofi Isyraqi Suhrawardi yang bersandar pada konsep cahayanya, termasuk istilah kuncinya, Nūr Al-Anwār (cahaya dari segala cahaya) yang menggambarkan konsepsi Tuhan.

\section{Metode}

Riset ini bersifat kualitatif (qualitative research). Objek penelitian ini adalah pemikiran tokoh dengan menggunakan data primer dan sekunder yang bersifat kualitatif. Data primer terdiri karya-karya primer tokoh yang dikaji, seperti Hikmat Al-Isyrāq, sedangkan data sekunder diambil dari sejumlah peneliti yang mengkaji pemikiran tokoh tersebut, baik secara langsung maupun tidak langsung. Adapun pendekatan dalam penelitian ini adalah historisfilosofis dan penyajiaanya bersifat deskriptif-analitis.

\section{Hasil dan Pembahasan}

\section{Sketsa Biografis Suhrawardi Al-Maqtul}

Dalam bentang sejarah pemikiran Islam, khususnya bidang tasawuf dan filsafat, terdapat beberapa tokoh yang nama Suhrawardi dinisbatkan kepadanya. Diantaranya Abu Najib Abdul Qadir Suhrawardi (w. 1168 M), Yahya Ibn Habbash Al-Suhrawardi (w. 1191 M), dan Umar Suhrawardi (w. 1234 M). Ketiganya dilahirkan di daerah yang sama, yaitu Suhrawand (Ohlander, 2008)). Abu Najib Abdul Qadir Suhrawardi (w. 1168) merupakan merupakan sufi yang lahir dari tradisi Syafi'iyyah-Asy'ariyyah. Ia merupakan pendiri Tarekat Suhrawardiyah dan penulis kitab Adab Al-Muridin. Suhrawardi kedua atau Suhrawardi yang nantinya digelari Al-Maqtūl (w. $1191 \mathrm{M}$ ) merupakan teosof atau pengembang ajaran tasawuf falsafi aliran Isyraqiyyah (iluminasionisme). Sedangkan Suhrawardi ketiga atau Syihabuddin Umar Suhrawardi merupakan sufi sekaligus ahli kalam murid Al-Ghazali yang menulis kitab 'Awārif Al Ma'ārif. Ia juga nerupakan keponakan dari Abu Najib Abdul Qadir Suhrawardi. Memahami ketiga Suhrawardi ini penting agar tidak terjadi kesimpangsiuran dan tumpang tindah informasi yang menghasilkan pemahaman yang keliru, sebab bahkan sebuah ensiklopedi berbahasa Arab pun salah paham, utamanya tumpang tindih informasi antara 
Suhrawardi kedua dan ketiga (Corbin, 1994: 205-206; Nasr, 1997: 150; Riyadi, 2016: 188-189, 233).

Adapun yang hendak dibahas pada tulisan ini ialah Suhrawardi Al-Maqtūl (w. 549-587 H/ 1153-1191 M). Terlahir dengan nama lengkap Yahya Ibn Habasy ibn Amirak Abu Al-Futūh, ia dianggap pemikir besar selepas Ibn Rusyd, bersama dengan Ibn 'Arabi. Pertumbuhan masa kecilnya tidak diketahui secara pasti, berbeda dengan Syihabuddin Umar Suhrawardi. Hanya beberapa sumber sejarah yang mencantum dan membahasnya, itupun tidak dianggap otoritatif sebab tidak begitu populer. Beberapa diantaranya dari Sayyiduddin Ibn Riqqah (w. 1237 M), Imad Al-Dīn Al-Isfahāni (w. 1201 M) penulis Al-Bustān Al-Jāmi' li Al-Tawārikh AlZamān, Ibn Asbi'ah (w. 1270 M) penulis 'Uyūn Al-Anba, Fakhr Al-Dīn Al-Mardinī (gurunya) dan Syams Al-Dīn Muhammad Syahrazuri (w. 1250 M) yang merupakan murid dan pensyarah utama ajaranya.

Sebagaimana disebutkan Ibn Abi Asbi'ah, Suhrawardi telah menunjukkan minat dan bakat keilmuan di bidang filsafat dan teologi. Namun ia tercatat tidak mendalami ilmu keislaman dasar seperti Al Qur'an dan hadis, serta fikih yang menjadi salah satu turunan utamanya. Bahkan dalam tasawuf ia belajar secara otodidak dan kepada gurunya-gurunya ia hanya belajar filsafat, teologi, metafisika, dan fisika. Ia belajar kepada Majd Al-Dīn Al-Jili di Maragha dan Fakhr Al-Dīn Al-Mardinī yang merupakan kawan dari Abu Al-Barakat AlBaghdādi (w.1164 M) yang banyak disebutnya nanti dalam Hikmat Al-Isyrāq. Al-Mardinī juga merupakan guru dari teolog Asyari terbesar setelah Al-Ghazāli (w. 111 M), Fakhr Al-Dīn AlRāzi (w. 1209 M). Ia juga ditengarai pernah mendalami logika kepada Zahir Al-Dīn Al-Qāri dan Umar Ibn Shalah Al-Shāwī. Dalam catatan Yūsūf ibn Taqhribirdī, dalam Al-Nujūm AlZāhirah fì Mulūk Misr wa Al-Qahirah, ia mencatat kesannya ketika bertemu Suhrawardi sebagai orang dengan wawasan yang luas dan pikiran kecil. Suhrawardi dikenal sebagai orang yang cukup berani menyebut dirinya superior dari pemikir lainnya, termasuk Ibn Sinā (Razavi, 1997: 1-2; Ziai, 2003: 545; Riyadi, 2016: 233).

Kecerdasan Suhrawardi amat tersohor, termasuk dalam amatan gurunya. Meskipun begitu, Al Mardini melihat suatu yang mengganjal dalam diri muridnya, yaitu soal pemikirannya yang dinilai liar dan gagasan yang seringkali konfrontatif dan destruktif. AlMardinī menulis sebagaimana dikutip Ibn Abi Asbi'ah (Riyadi, 2016: 234):

"Kegemarannya dalam berdialektika dan mengungkapkan gagasan yang melawan yang arus benarbenar mengkhawatirkan saya. Pemikirannya yang cukup luarbiasa namun liar, dapat mencelakakannya dan menghancurkannya pada saatnya nanti."

Pada akhirnya apa yang ditakutkan oleh sang guru terjadi. Kisahnya tragis seperti AlHallāj (w. 922 M), juga Ain Al-Qudhāt Hamadhānī (w. 1131 M), baik pikiran dan sikap kontroversialnya juga peristiwa kematiannya. Ia dieksekusi atas perintah Shalah Al-Dīn AlAyyūbi pada di Aleppo (Halb), setelah para ulama zamannya baik dari elemen hakim, wazir, ahli fikih mengajukan tuduhan kepadanya yang disampaikan oleh Qādhi Al-Fādhil kepada sang sultan. Meskipun pada waktu ia tengah dekat dengan putranya, Pangeran Malik AlZāhir, eksekusi tetap dilaksanakan karena ia juga dianggap membahayakan pangeran karena dianggap zindiq. Adapun tuduhan ini meskipun berbau politik, memiliki argumentasi yang kuat bila melihat sejumlah pemikiran Suhrawardi yang menyimpang dari pakem yang ada, dari konsep tauhidnya yang panteistik, posisinya atas kenabian dan wali, serta ketidakjelasan posisinya terhadap wahyu (Dabashi, 2003: 466-543; Razavi, 2003: 4; Ziai, 2003: 545-546).

Mengenai konteks Intelektualnya, Suhrawardi hidup saat ajaran taswawuf ortodoks sedang berkembang, terutama Tarekat Qādiriyyah (dinistbatkan kepada Abd Al-Qādir AlJilāni) dan Tarekat Syādzilīyyah (dinisbatkan kepada Abu Al-Hasan Al-Syādzilī) serta ajaranpemikiran murid-murid intelektualnya. Keduanya merupakan tarekat yang terikat kuat dengan syariat atau belakangan distilahkan menjalankan ajaran Tasawwuf Akhlāqi. Meskipun begitu, ajaran dan pengajaran filsafat Yunani tidak sepenuhnya padam, sehingga dikemudian hari pikiran-pikiran alam Yunani ini mempengaruhi 'model baru' tasawuf yang bercorak filosofis dan cukup sistematis. Salah satunya adalah Tasawuf Falsafi aliran Isyrāqi (Iluminasionisme) yang digagas Suhrawardi (Nasr, 1997: 460-461; Baghir, 2018: 69-70). 
Adapun, sebelum era kecenderungan tasawuf menguat ini, para filsuf, terutama mazhab paripatetik yang mendapatkan momentumnya dibawah kekuasaan Dinasti Abbasiyah, terutama abad 9-10 M, hingga kemunculan Al-Ghazali (Nasr, 1997: 52-54).

Disisi lain, diwaktu yang sama, beberapa saat sebelum kemunculan Suhrawardi, juga terjadi pembersihan terhadap ajaran-ajaran menyimpang yang menyesatkan di Baghdad oleh sejumlah ahli hadis, termasuk masuknya animisme dan pikiran-pikiran lainnya dalam tubuh tasawuf. Tokoh utama saat itu adalah Ibn Al-Jauzī, seorang ulama besar abad ke-12 M yang menulis ratusan kitab. Salah satu karya magnum opusnya yang berjasa menjernihkan tasawuf ialah Talbīs Iblīs. Suhrawardi tidak bertemu secara langsung dengan Ibn Al-Jauzī, sehingga tidak menjadi sasaran kritiknya. Namun meskipun begitu ajaran-ajaran yang dijadikan sumber oleh Suhrawardi telah dikritik oleh Ibn Al Jauzi, termasuk Abu Al-Barakāt AlBaghdādi yang mempengaruhinya (Riyadi, 2016: 234-235). Momentum yang diciptakan oleh Suhrawardi pada gilirannya merupakan kelanjutan pengembangan filsafat juga tasawuf yang memasuki fase barunya, yaitu tasawuf falsafi, meskipun disisi lain juga terjadi gerakan pemurnian disisi lain, terutama di kalangan Sunni, lewat Ibn Taimiyyah dan muridnya, Ibn Al-Qayyim Al-Jauziyyah serta penerusnya.

Suhrawardi merupakan penulis produktif dalam filsafat, meskipun harus meninggal di usia muda. Terdapat sekitar 49 karya yang dihasilkan oleh Suhrawardi dalam bahasa Arab dan Persia (Nasr, 1997: 58; Riyadi, 2016: 242). Nasr membagi sejumlah karyanya ke dalam lima kategori, yaitu (1) empat karya doktrinal utamanya, yaitu Al-Talwihāt, Al-Muqāwamāt, Al-Masyhāhari wa Al-Muthārahāt, dan Hikmah Al-Isyrāq; (2) risalah-risalah ringkas yang membicarakan tetraloginya secara ringkas dan sederhana, diantaranya Hayākil Al-Nūr, AlAlwāh Al-'Imādiyyah, dan Patraw Namah; (3) kisah-kisah mistik dan simbolik, Diantaranya Awaz-I par-I Jibra'il, 'Aql-Isurkh, dan Al-Ghurbāt Al-Gharbiyyah; (4) transkripsi, terjemahan, dan uraian atas karya-karya filsafat yang lebih awal, seperti Risalat Al-Thayr Ibn Sina dan Risalat $f i$ Al-'Isyq Ibn Sina; dan (5) doa-doa dan permohonan dalam bahasa Arab, seperti Al-Wāridat wa Al-Taqdīsāt. Empat karya terpentingnya, yaitu Al-Talwihāt, Al-Muqāwamāt, Al-Masyhāhari wa Al-Muthārahāt, dan Hikmah Al-Isyrāq, terutama pada dua yang terakhir, Suhrawardi memberikan pengantar mengenai metodologi filsafat ilmuninasi (Ziai, 2003: 54).

\section{Pemikiran Filsafat Suhrawardi}

a. Konsep Dasar Suhrawardi: Tuhan dan Cahaya

Konsep dasar Suhrawardi tidak bisa dilepaskan dari pembacaanya terhadap karya AlGhazalī, Misykāt Al-Anwār. Dalam karya ini, Al-Ghazalī mengulas secara dalam makna cahaya yang ada dalam Al-Qur'an dan hadis ke dalam pembahasan filosofis, namun ditunjang oleh naskh ('aql bi al-naql). Secara garis besar, ia membahas tiga penjelasan utama berkaitan dengan (1) hakikat cahaya, (2) perumpamaan-perumpamaan yang berhubungan cahaya dalam Al-Qur'an, dan (3) Hijab antara Allah SWT dan makhluq-Nya (Al-Ghazali, 1987). Bila dibandingkan dengan karya pamungkas dari tetralogi Suhrawardi, Hikmah AlIsyrāq, secara menarik dapat ditemukan beberapa adopsi juga perubahan atau terjadi transmisi sekaligus transformasi. Diantara hal yang tidak berubah, ialah bahwa cahaya menjadi suatu yang sebenarnya hanyalah Allah SWT (ontologi cahaya), dan selainnya adalah yang terkena sinarnya. Al-Ghazalī misalnya menyebutkan:

$$
\text { أن النور الحق هو الله تعالى وأن اسم النور لغيره مجاز محض لا حقيقة له }
$$

(Al-Ghazali, 1987: 26)

Sedangkan dalam Hikmāh, Suhrawardi menulis:

$$
\begin{aligned}
& \text { أن النور لا يحتاج إلى تعريف ـ إن كان فى الوجود ما لا يحتاج إلى تعريه وشرحه فهو الظاهر , و لا شيئ } \\
& \text { أظهر من النور ,فلا شيئ أغنى منه العريف }
\end{aligned}
$$


(Suhrawardi, 1999: 76; 2010: 68)

Adapun hal-hal yang mencolak dan berbeda terletak pengembangan, yaitu pada istilahistilah teknisnya yang baru dan lebih banyak juga beragama dan penjelasan dengan perbedaan metode dengan Al-Ghazalī, terutama dikurangi porsi nash (naql) digantikan oleh nalar kreatif-modifikatif dan pengetahuan-pengetahuan kuno yang disebutnya $\mathrm{Al}$ - $\mathrm{Hikmah} \mathrm{Al}$ Khālidah.

Suhrawardi secara khusus juga menggunakan istilah Nūr Al-Anwār (cahaya dari cahayacahaya) untuk menunjuk esensi Ilahi yang menyebabkan pancaran ilahiyah sehingga yang lain adalah pancarannya dengan tingkatan dan intensitas berlapis-lapis. Baginya semesta dalam seluruh latar realitasnya merupakan tingkatan dan intensitas-intensitas cahaya tersebut. Sehingga status ontologis (ada) segala sesuatu bergantung dari tingkatan dan intensitas keterpancaran dari Nūr Al-Anwār (Suhrawardi, 2010: 68-103). Konsep Tuhan sebagai cahaya dari segala cahaya ini menjadi pokok dasar dari konsep teosofinya yang berpengaruh pada tema-temanya teosofinya, praktek sufistiknya, dan epistemologinya.

b. Sumber-Sumber Pemikirannya

Suhrawardi memiliki perjalanan intelektual yang unik dan hal tersebut menjelaskan sumber-sumber pemikirannya yang sinkretik, untuk tidak mengatakan eklektik. Setidaknya ada lima sumber utama pemikiran Suhrawardi (Nasr, 1997: 158-159; Bagir, 81-82), yaitu (1) Tasawuf, termasuk tasawuf Al-Ghazalī dan Al-Hallāj, (2) Peripatetisme/ Arabo Aristotelianisme, (3) Platonisme, Neo-Platonisme dan Pythagoreanisme atau mistisme Yunani, (4) Hermetisme, dan (5) Kepercayaan Zoroasterianisme.

Pemikiran iluminasi Suhrawardi terelesai dengan pengetahuan kuno, termasuk Yunani, Hermes Mesir, Zoroaster, dan Buddha yang dianggap memiliki 1 kebijaksanaan ilahiah ( $\mathrm{Al}$ Hikmah Al-Laduniyyah) dan kebijaksanaan kuno (Al-Hikmah Al-'Átiqah) yang bersifat universal-abadi (universal-philosophia perennis). Secara khusus S.H. Nasr menyebutkan rangkaian alur pemikiran Suhrawardi terhubung dengan Hermes \& Agathedemon (Seth) melalui dua jalur, yaitu (i) Asclepius - Pythagoras - Empedocles - Plato (dan Neo-Platonis) Dzu Al-Nūn Al-Mishrī-Abū Sahl Al-Tustarī dan (ii) Raja-raja Persia - Kayūmarth - Farīdūn Kai Khusraw - Abū Yazīd Al-Busthāmī - Mansur Al-Hallāj - Abu Al-Hasan Al-Kharraqān̄̄ (Rayyan, 1959: 52-100; Walbridge 2001; Nasr, 1997: 62).

\section{c. Perkembangan Pemikirannya}

Prinsip dasar pemikirannya ditujukan sebagai sesuatu yang bersifat sintetik dan sinkretik (ketimbang eklektik). Dalam mendapatkan kebenaran ia menempuh jalan pengalaman intuitif, kemudian mengelaborasi dan memverifikasinya secara logis-rasional atau dengan kata lain pengetahuan didapatkan lewat pengalaman intuitif (pengetahuan presensial) kemudian dianalisis secara diskursif-demonstrasional. Hal ini direkonstuksi dari perjalanan intelektualnya yang melompat-lompat. Pada awalnya ia merujuk Al-Ghazalī lewat karya Misykāt Al-Anwār, bukan lewat Ihyā 'Ulūm Al-Dīn atau Tahāfut Al-Falāsifah. Tidak seperti Ihyā yang cenderung kepada Tasawuf Syar'I atau Akhlaqi dan Tahafut yang mengkritik metafisika para filsuf, lewat Misykāt ia menemui jalan lain untuk terhubung kepada khazanah filsafat Yunani Kuno. Meskipun Al Ghazali biasa dianggap sebagai tokoh antagonis, justru lewat AlGhazali ia mengenal para filsuf terdahulu dan pemikirannya, dari Al-Kindī, Ibn Sinā, Ikhwān Al-Shafā, Aristoteles, dan Plato. Namun, pengaruh Al-Ghazali Al-Ghazalī cukup sampai disitu, ia kemudian mendalami pikiran para filsuf peripatetik. Hal ini dianggap mempengaruhi pandangan ekstremnya soal kenabian (Riyadi, 2016: 238-239). Namun, dititik ini pun ia masih kebingungan, sebagaimana ia sampaikan dalam Al Muthāharāt dan dikutip oleh Abdul Rahman Al Badawi:

"Beginilah. Saya saya sudah hampir berusia 30 tahun dan sebagian besar umurku aku habiskan berkelana mencari ilmu. Tetapi, hingga kini aku belum menemukan orang yang cukup cakap dalam penguasaannya terhadap ilmu-ilmu yang mulia yang aku cari." 
Ungkapan ini ditulis pada tahun $1185 \mathrm{M}$, dua tahun setelah menetap di Aleppo dan setahun sebelum magnum opusnya terbit, Hikmah Al Isyraq. Pernyataannya ini cukup kontroversial sebab seakan menganggap kecil, nama-nama besar. Pada akhirnya ia mencampakkan sejumlah filsfuf yang pernah menjadi guru intelektulanya dan akhirnya tiba pada Plato. Dititik inilah ia merasa amat kagum dan terpengaruh oleh Plato, bahkan memuja-mujanya. Ia menulis:

"Ahli teologi bernama Plato ini lebih menonjol dan pandai dari seluruh pemikir dan ulama muslim yang pernah saya ketahui. Apakah ada di antara pemikir dan ulama muslim yang dapat mencapai derajat setara dengan Plato? Tidak ada. Bahkan tidak satu pun dari mereka yang mampu mencapai seribu tingkat dibawah Plato.

Pernyataan ini tentunya amat kontroversial karena amat merendahkan pemikir dan sarjana muslim lainnya. Pada titik berikutnya, perjalanannya juga mengantarkannya pada Aristoteles yang ia anggap sebagai guru kedua dan guru spiritualnya. Inilah sisi unik Suhrawardi. Ia seakan menemukan "tasawuf" melalui sejumlah filsuf, tidak dengan jalan salik sebagaimana yang dilakukan oleh sufi tarekat pada umumnya atau sufi dalam pengertian tasawuf akhlaqi lewat pelaksaan akhlaq sehari-hari (Riyadi, 2016: 239-240).

Dalam sebuah kesempatan, sebelum karya terakhir dan monumentalnya dimana ia telah menemukan model berpikirnya yang dapat dianggap matang, ia bermimpi bertemu Aristoteles. Dalam mimpinya ia diarahkan oleh sang "guru kedua" untuk diantara guru sufi yang layak dijadikan gurunya Abū Yazīd Al-Busthāmī dan Mansur Al-Hallāj. Hal ini mirip dengan kisah Ibn 'Arabi sebelum menulis Fushūsh A-Hikām, yang ia temui adalah Nabi Muhammad SAW. Hal inilah yang menyebabkan ia akan berbicara soal hulül, ittihad, dan wahdhat Alu-Wujūd. Dititik inilah puncak kontroversi dan sinkretiknya, alih-alih mempertemukan semua perbedaan tajam pandangan pemikir yang menginspirasinya ia mengambil yang sesuai baginya, sehingga menimbulkan reaksi dari berbagai kalangan. Tujuannya berfilsafat lewat tasawuf sedemikian rupa dengan mencari ilmu yang sebenarnya atau Al-'Ilm Al-Haqì $\bar{\imath}$ juga menimbulkan kekaburan orientasnya apakah itu sebuah kebenaran agama, sufistik, atau filosofis (Riyadi, 2016: 241).

\section{d. Karakter Filsafatnya}

Adapun mengenai karakter khas filsafatnya ialah menjadi cahaya sebagai pusat simbolik yang menggantikan berbagai istilah filsafat peripatetik, yang meneguhkan sistem barunya. Diantaranya Qāidah Isyrāqiyyah (kaidah iluminasionis), Dhawābith Isyrāqiyyah (aturan-aturan ilmunasionis), Daqīqah Isyrāqiyyah (argumentasi-argumentasi iluminasionis), Musyāhadah Isyrāqiyyah (visi iluminasionis), Idhāfah Isyrāqiyyah (hubungan iluminasionis), Al-'Ilm AlHudhūrī Al-Isyrāqi (pengetahuan iluminasionis melalui kehadiran). Hossein Ziai menyebutkan bahwa baginya filsafat Iluminasi merupakan upaya rekonstruksi sistematis filosofis dengan tujuan tujuan untuk menghindari inkonsistensi-inkonsistensi logis, epistemologis, dan metafisis yang dirasakan Suhrawardi pada mazhab Peripatetik (Ziai, 2003: 549-550).

Mengenai epistemologinya, Hossein Ziai menulis bahwa prinsip dasar filsafat iluminasi ialah bahwa mengetahui sesuatu berarti memperoleh pengalaman tentangnya, serupa dengan intuisi primer terhadap determinan-determinan sesuatu. Pengetahuan tentang sesuatu lanjutnya, dapat dianalisis hanya setelah pengalaman intuitif yang total dan langsung. Ia menegaskan dalam pengantar Hikmah A-Isyrāq bahwa (Suhrawardi, 2010: 2):

"aku mula-mula, tidak memperolehnya (filsafat ilumniasi) melalui berpikir, tetapi melalui sesuatu yang lain, aku mencari pembuktian-pembuktian lebih lanjut baginya"

Teori pengetahuan Suhrawardi ini merupakan konsep yang direkonstruksi atas sejumlah pertimbangan intuitif ( $A l$-Ahkām Al-Hads-yang mirip gagasan agkhinoia Aristoteles) dan apa yang ia nilai sebagai proses ganda ilmuninasi (Al-Musyhādah wa Al-Isyrāq) yang berfungsi bagi landasan rekonstruksi ilmu yang kuat dan benar ( $A l$-' Ilm $A l$-Shahīh). Aspek-aspek ini juga yang membentuk metode ilmu pengetahuan (Thariq Al-'Ulüm) yang merupakan inti Filsafat Suhrawardi tentang pengetahuan presensial. Baginya pengetahuan visioner mengantarkan pada pengetahuan yang tidak dapat diperoleh melalui proses berpikir ( $f i k r)$ dan berlangsung 
dalam 'Alām Mitsāl (mundus imanginalis). Alam ini ialah alam ontologis, dimana wujud meski memiliki kategori, namun bebas materi. Ia sering membandingkan antara Irsyād Jasmani (astronomis fisikal) dan Irsyād Ruhani (astromis spiritual), lalu menyatakan perolehan dari kedua pengamatan ini adalah sama. Suhrawardi menganggap kategori-kategori seperti substansi, kualitas, kuantitas, relasi, dan gerak merupakan tingkatan intesitas proses-proses, tidak sebagai entitas ontik berbeda dan secara simbolis ini digambarkan oleh cahaya (Ziai, 2003: 569-571; Bagir, 2018: 112-115).

Lebih lanjut pasca kisah mistiknya bertemu Aristoteles dan kembali diarahkan olehnya kepada para mistikus kontroversial, seperti Al-Hallāj dan Abū Yazīd Al-Busthāmi, ia mendapati kesadaran kedirian merupakan dasar-dasar pijakan pengetahuannya. Kesadaran awal akan esensi diri ialah jalan pengetahuan yang disebut sebagai Al-'Ilm Al-Hudhuri AlSyuhū $\bar{l}$ (pengetahuan dengan kehadirian dan penglihatan). Baginya ini tingkatan pengetahuan yang jauh lebih tinggi dari perolehan kaum peripatetik yang bertumpu pada kesatuan akal aktif. Suhrawardi menyebutkan dua kaidah utamanya berkaitan dengan landasan pengetahuan, yaitu Man syahadu al-syai, istaghna 'an al-ta'rîf (jika sesuatu dapat dilihat, tidak perlu mencari definisinya) dan shuratuhu fi al-'aql ka shurātihi fi al-hiss (bentuk sesuatu dalam pikiran sama bentuknya dengan persepsi indera). Dalam metode iluminasionis, mempeoleh pengetahuan melalui modus khusus persepsi jauh lebih tinggi dari pengetahuan predikatif, karena subjek mempunyai pengetahuan langsung tanpa perantara. Pandangan ini dasari doktrin kesatuan subjek dan objek, melalui gagasan tentang objek yang diperoleh pada kesadaran subjek. Suhrawardi berargumen bahwa korespondensi utuh antara subjek dan objek memperlihatkan pengetahuan tentang sesuatu sebagaimana adanya (Ziai, 2003: 572-573).

Adapun mengenai tahap-tahap perolehan pencerahan (iluminasi) ini melalui empat tahap. Tahap pertama, seseorang harus membebaskan diri dari kecenderungan diri dan duniawi untuk menerima pengalaman ilahiah. Dalam diri seseorang sebut Suhrawardi terdapat AlBāriq Al-Ilāhi atau kilatan Tuhan. Kilatan ini perlu diaktifkan dengan uzlah selama 40 hari. Tahap kedua, seseorang penempuh jalan atau al-thālib al-Isyrāqi ini akan mendapatkan sinar ketuhanan (Al-Nūr al-Illāhi) serta mendapatkan cahaya ilham (Al-Anwār Al-Sanīhah). Tahap ketiga, merupakan proses pembangunan pengetahuan yang utuh, didasarkan atas logika diskursif. Tahap keempat ialah pengungkapan atau penulisannya (Bagir, 2018: 82).

\section{Magnum Opus Suhrawardi: Hikmah Al-Isyrāq}

Mengenai magnum opusnya, Hikmah Al Isyraq, terdiri dari bagian 2 utama, yaitu prinsipprinsip berpikir (Dhawabit Al Fikr) dan cahaya-cahaya ilahi, cahahaya maha cahaya, prinsipprinsip eksistensi, serta hierarkinya ( $f i$ Anwar Al Ilahiyyah wa Al Anwar wa Mabadi Al Wujud wa tartibiha). Bagian pertama, membahas 3 tema, yaitu (1) Objek-objek pengetahuan dan definisi, (2) argumentasi dan prinsp-prinsip mendasar, dan (3) penolakan sofistik dan sebagian pertanyaan yang beredar dikalangan mazhab. Bagian kedua, meliputi (1) Cahaya Esensinya, Cahaya Mahacahaya dan Yang Pertama Kali Beremanasi Darinya; (2) Hirarki Eksistensi; (3) Bentuk Tindakan Cahaya Mahacahaya dan Cahaya-cahaya Pemaksa Disertai Diskripsi Pelengkap Tentang Gerakan-gerakan Lagit; (4) Pembagian Barzakh, Kualitas, Komposisi dan Sebagian Fakultasnya; (5) Kebangkitan Eskatologis (al-ma'ad), Profetologi dan Mimpi-mimpi (Suhrawardi, 2010: vii-viii).

Pada bagian pertama, kita akan dapati bahwa prinsip filsafat iluminasi Suhrawardi didasarkan pada kesadaran diri tentang diri (anniyah) yang juga bersifat intuitif. Model ini memberikan kritik terhadap model diskursif-rasionalistik mazhab peripatetik. Baginya pegetahuan model peripatetik dalam rangkaian proses definisi mahiyyah (esensi)-proposisisilogisme hanya akan mencapai tahap idrak atau persepsi, sehingga esensi objek belum tertangkap. Secara umum dia memberikan banyak koreksi pada bagian ini, utamanya kepada mazhab peripatetik.

Pada bagian kedua membahas kepada sistem filsafatnya yang bermula dari pandangan spesifik bahwa Allah adalah Nür Al-Anwār (Cahaya dari segala cahaya). Istilah ini 
menggantikan istilah wajib al-wujud-nya aliran peripatetik. Ia terinspirasi dari Q.S Al Nur [24]: 35 (Suhrawardi, 2010: 2), yang berbunyi:

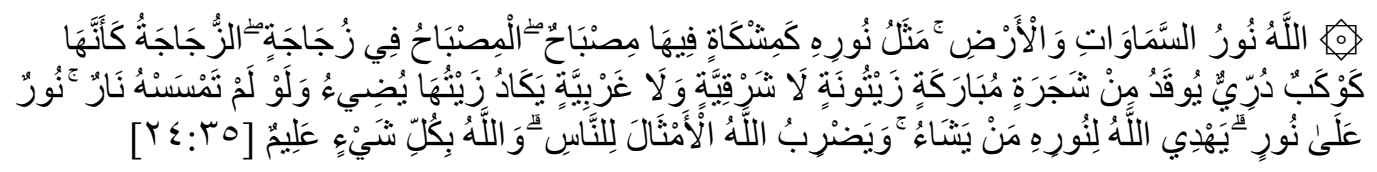

35. Allah (Pemberi) cahaya (kepada) langit dan bumi. perumpamaan cahaya Allah, adalah seperti sebuah lubang yang tak tembus[1039], yang di dalamnya ada pelita besar. pelita itu di dalam kaca (dan) kaca itu seakan-akan bintang (yang bercahaya) seperti mutiara, yang dinyalakan dengan minyak dari pohon yang berkahnya, (yaitu) pohon zaitun yang tumbuh tidak di sebelah timur (sesuatu) dan tidak pula di sebelah barat(nya)[1040], yang minyaknya (saja) Hampir-hampir menerangi, walaupun tidak disentuh api. cahaya di atas cahaya (berlapis-lapis), Allah membimbing kepada cahaya-Nya siapa yang Dia kehendaki, dan Allah memperbuat perumpamaan-perumpamaan bagi manusia, dan Allah Maha mengetahui segala sesuatu.

Dari ayat ini lahirlah konsep cahaya dalam hakikat dirinya (Nür fi haqiqat nafsih), sesuatu yang bukan cahaya dalam hakikat dirinya (ma laisa bi nūr fi haqiqah), dan cahaya dalam dirinya (Al-Nūr Al-Mujarrad). Konsep cahaya ini juga lebih memungkin pengambaran konsep kedekatan (qurb) dan kejauhan (bu'd) lewat hierarki yang ditentukan oleh intensitas. Semakin dekat sesuatu dengan Nūr Al-Anwār (cahaya dari segala cahaya), maka semakin sempurna wujudnya. Artinya tingkatan cahaya sejalan dengan tingkatan wujud. Cahaya dari segala cahaya ini juga digambarkan sebagai Al-Nūr Al-Muhìth (cahaya uang Maha Meliputi), Al-Nür Al-Qayyūm (cahaya yang Maha Menguasai), Al Nūr A'zam (cahaya yang Maha Agung), AlNür A'la (cahaya yang Maha Tinggi), dan Al-Nūr Al-Qahhar (cahaya yang Maha Memaksa). Sebagai konsekuesi, konsep hierarki ini terbagi kepada 3 pokok, yaitu cahaya, kegelapan, dan barzakh (penyekat antar tiap cahaya). Inilah yang membuatnya diidentifikasi menghidupkan filsafat kuno Persia, yang sifatnya dualistis, termasuk konsep cahaya dan kegelapan.

\section{Al-Suhrawardi Al-Maqtul dan Tradisi Iluminasi}

Meskipun meninggal dalam usia yang muda, Suhrawardi dengan karyanya memberikan dampak yang cukup besar pada perkembangan setelahnya. Menurut Abdul Kadir Riyadi (2016), suatu pemikiran dapat dikatakan hebat bila melampaui zamannya dalam artian jika dapat bertahan dalam waktu yang lama di tengah guncangan, hujatan, dan penolakan. Singkatnya dalam jangka waktu yang masih memiliki konservator, bahkan pensyarah.

Ide Iluminasionisme Suhrawardi setidaknya mengalami 4 hal, sehingga dapat dikatakan gagasab besar. Pertama, ia bertahan dalam waktu yang lama. Bila dihitung dari masanya hingga ke masa kita terdapat rentang 900 tahun. Kedua, idenya pernah lenyap dan terlahir kembali. Ketiga, pernah tidak anggap pada suatu masa, namun mendapatkan pengakuan kemudian. Keempat, diakui dalam konteks berbeda oleh jaringan pemikiran tasawuf jaringan Prancis, dari Louis Massignon, Henry Corbin, Abdul Rahman Badawi, dan Muhammad Ali Abu Rayyan (Riyadi: 2016, 243).

Suhrawardi memiliki komentator dari masa ke masa. Pada abad ke-7 H/13 M muncul tiga komentator terbesarnya, yaitu Syams Al-Dīn Al-Syahrazūrī, penulis Nuzhāh Al-Arwāh wa Al-Raudhāh Al-Afrāh (w. 1288 M), Sa'd Mansūr Ibn Kammūnah, penulis Al-Jadīd fï Al-Hikmah (w.1254 M), dan Qutb Al-Dīn Al-Syirāzi, penulis Durrah Al-Tāj (w. $1311 \mathrm{M}$ ). Pada abad ke-9 H/ 15 M muncul Muhammad Ibn Zayn Al-Dīn Ibn Ibrahīm Ahsā'I (w. 1479 M) dan Jalāl AlDīn Al-Dawāni, penulis Syawākil Al-Hūr fi Syarh Hayākil Al-Nūr (w.1501 M). Pada abad ke-10 H/ $16 \mathrm{M}$ muncul Ghiyats Al-Din Manshur Daystaki (w. 1541 M). Pada abad ke-11 H/ 17 M muncul Muhammad Syarīf Nizhām Al-Dīn Al-Harāwi, Muhammad Bāqir Ibn Syams Al-Dīn Muhammad/ Mīr Damād (w. 1631 M), dan Shadr Al-Dīn Al-Syīrāzī/ Mullā Sadrā (w. 1640 M). Pada abad ke-14 H/ 20 M muncul Sayyid Muhammad Kāzhim 'Assyār. Meskipun begitu tren tradisi iluminasi secara umum, terbagi menjadi dua, yaitu Syahrazūrī dan Ibn Kammūnah, sebelum versi sintesis Mullā Sadrā dengan Filsafat Hikmah, Syahrazūrī menekankan pada aspek unsur khas anti paripatetik dan simbolis filsafat iluminasi serta mengembangkan aspek iluminasi dengan memperluas sisi insipiratif, alegoris, dan fantastis. 
Sedangkan Ibn Kammūnah menekankan aspek diskursif murni dan aspek filosofis sistematis dari filsafat iluminasi (Ziai, 2003: 579-616).

\section{Suhrawardu Al-Maqtul: Kontribusi dan Posisinya dalam Filsafat Islam}

Secara umum, Filsafat Iluminasi Suhrawardi memberikan pengaruh dan kontribusi yang cukup signifikan dalam Filsafat Islam secara luas, dan secara khusus di tradisi Syi'ah. Meskipun begitu Mehdi Amin Razavi mencatat, Suhrawardi memiliki pengaruh secara luas di Persia, India, Syria, Anatolia, bahkan Barat. Dalam konteks Persia ia memberikan kontribuasi besar pada Mazhab Isfahan, Mazhab Sadrian, Mazhab Qajar, dan Mazhab Syaikhiyyah bahkan hingga Filsafat Iran Modern yang terus dimatangkan (Razavi, 1997: 122136).

Dalam konteks India, karyanya diterjemahkan ke dalam bahasa Sanskrit oleh komunitas Zoroaster. Tersebarnya Filsafat Iluminasi juga ditopang oleh ketertarikan dan penguasa, utamanya pada abad ke-14 M oleh Sultan Muhammad Tughlag. Nama lain yang juga turut berperan dalam menyebarkan Filsafat Iluminasi, yaitu Sand Nizām Al-Dīn yang mengkaji teks-teks syarah dari karya Suhrawardi pada awal abad ke-15 M yangkemudian dilanjutkan oleh muridnya, Abū Al-Fadhl Kāzirūnī (Razavi, 1997: 137-139). Dalam konteks Syria dan Anatolia, karya-karya Suhrawardi ditemukan di perpustakaan sarjana Turki, termasuk manuskrip-manuskrip yang dirujuk oleh orientalis, seperti Henry Corbin. Karyanya juga dipelajari dalam lingkaran-lingkaran komunitas Isyrāqi (Razavi, 1997: 139-140).

Adapun di Barat, disebutkan memberikan kontribusi dalam perkembangan Mistisme Yahudi (Kabbalah) dan lingkar sarjana Oxford abad ke-13 (Roger Bacon dan Robert Grossteste. Ia juga dianggap memiliki pengaruh secara tidak langsung terhadap kemunculan eksistensialisme dan humanisme. Kajian terhadapnya dan tradisi filsafatnya secara khusus mendapat perhatian dari pemikir tasawuf jaringan Prancis, seperti Louis Massignon dan Henry Corbin (Razavi, 1997: 137-139, 141; Riyadi, 2016: 247) serta dilanjutkan oleh cendekiawan muslim produk pendidikan Barat, seperti Abdul Rahman Badawi, Muhammad Ali Abu Rayyan, Hossein Ziai, Mehdi Hairi Yazdi, dan Sayyid Hossein Nasr.

\section{Kesimpulan}

Sebagai penutup ada beberapa poin yang penulis sampaikan. Pertama, Tidak diragukan bahwa Suhrawardi merupakan salah sufi-filsuf yang paling berpengaruh dalam tradisi Mistik Islam. Pemikirannya ditujukan sebagai usaha eklektik-sintetik untuk menuju 'kebenaran sejati', meskipun lebih terlihat sinkretik pada akhirnya. Kedua, pikirannya tentang Tuhan dalam kerangka sistem cahaya sebenarnya merupakan hasil refleksi yang berakar pada tradisi kuno (Yunani, Suryani, Parsi, Hermes, dan Hindi) juga sekaligus nash-nash dalam AlQur'an, meskipun begitu penjabarannya yang berbeda dengan Al-Ghazali, inspirasi awal pemikirannya, membawanya kepada satu titik berbeda dan kontroversial yang mengakibatkan dirinya dieksekusi mati. Ketiga, potret hidupnya memang nampak tragis, namun buah gagasannya terus berkembang dan didiskusikan, bahkan dalam lintas tradisi dan geografis. Sebagai usaha intelektula selayaknya patut diapresiasi, disamping dikritik.

\section{Daftar Pustaka}

Açikgenç, Alparslan. (2014). Islamic Scientific Tradition in History. Kuala Lumpur: IKIM.

-----. (1996). Islamic Towards A Definition. Kuala Lumpur: ISTAC, 1996.

Al-Attas. (1963). Some Aspects of Sufisme As Understood and Practised Among the Malays, editor: Shirle Gordon. Singapore: Malaysian Socilogical Reseach Institute.

. (1966). The Mysticism of Hamzah Fansūri- thesis dissertation. London: SOAS.

Al-Ghazalī. (1987). Misykāt Al-Anwār, editor: 'Abd Al-'Azīz Al-Dīn Al-Sirwāni,. Beirut: 'Ālām Al-Kutub

Bagir, Haidar (2018). Epistemologi Tasawuf. Bandung: Mizan. 
Corbin, Henry. (1994). Corbin. History of Islamic Philosophy, translated by Liadain Sherrard. London: Kegan Paul International.

-. (1971). The Man of Light in Iranian Sufism, translated from French by Nancy Pearson. New York: Omega Publications.

Dabashi, Hamid. (2003)."'Ain Al-Qudhāt Hamadhāni dan Iklim Intelektual Masanya", dalam dalam Sayyid Hossein Nasr \& Oliver Leaman (ed.), Ensiklopedi Tematis Filsafat Islam: Vol. I, terjemah: Tim Penerjemah Mizan. Bandung: Mizan.

Gutas, Dimitri. (1988). Avicenna and the Aristotelian Tradition. Leiden: E.J Brill.

-----. (2005). Greek Thought, Arabic Culture: The Graeco-Arabic Translation Movement in Baghdad and Early 'Abbāsid Society 2nd-4th/8th -10th. London: Routledge.

Fakhry, Majid. (2000). Islamic Philosophy, Theology, and Mysticism: A Short Introduction. Oxford: Oneworld.

Nasr, S.H. (1997). Three Muslim Sages. New York: Caravan Books.

------. (2003)." Tradisi Mistis: Sebuah Pengantar", dalam Sayyid Hossein Nasr \& Oliver Leaman (ed.), Ensiklopedi Tematis Filsafat Islam: Vol.I. Bandung: Mizan.

O'leary, Delacy. (2016). How Greek Science Passed to The Arabs. New York: Routledge.

Ohlander, Erik S. (2008). Sufism in an Age of Transition: 'Umar Al-Suhrawardī and the Rise of Islamic Mystical Brotherhoods. Leiden: Brill

Rahman, Fazlur. (2002). Islam 2nd. Chicago: The University of Chicago Press, 2002.

Rayyan, Muhammad Ali Abu. (1959). Ushūl Al-Falsafah Al-Isyrāqiyyah 'Inda Syihāb Al-Dīn Al-Suhrawardī. Kairo: Maktabah Al-Anbalu Al-Mishriyyah

Razavi, Mehdi Amin (1997). Suhrawardi and The School of Illumination. Richmon Surrey: Curzon Press.

Riyadi, Abdul Kadir. (2016) Arkeologi Tasawuf. Bandung: Mizan.

Saeed, Abdullah. (2004). Islamic Thought: An Introduction.London: Routledge.

Suhrawardī, Syihab Al-Dīn. (2010). Hikmah Al-Isyrāq, editor: In'ām Haydūrah. Beirut: Dār Al-Ma'ārif Al-Hikmiyah.

------. The Philosophical Allegories and Mystical Treatises, A Parallel Persian -English Text Edited and Translated by Wheeler M. Thackston, Jr. California: Mazda Publishers, 1999.

-----. Hikmah Al-Isyrāq (The Philosophy of Illumination), english translation with original text oleh Hossein Ziai \& John Walbridge, (Utah: Brigham, University Press, 1999.

Walbridge, John. (2001). The Wisdom of the Mystic East: Suhrawardi and Platonic Orientalism. New York: State University of New York Press.

Ziai, Hossein. (2003). "Tradisi Iluminasionis" dalam Sayyid Hossein Nasr \& Oliver Leaman (ed.), Ensiklopedi Tematis Filsafat Islam: Vol. I. Bandung: Mizan.

-----. (2003)." Syihab Al-Din Suhrawardi: Pendiri Mazhab Iluminasionis" dalam Sayyid Hossein Nasr \& Oliver Leaman (ed.), Ensiklopedi Tematis Filsafat Islam Vol. I. Bandung: Mizan. 